\title{
Family history of myocardial infarction, stroke and diabetes and cardiometabolic markers in children
}

\author{
Nina E. Berentzen ${ }^{1,2}$ • Alet H. Wijga ${ }^{1}$ • Lenie van Rossem ${ }^{2}$ • Gerard H. Koppelman ${ }^{3}$ • \\ Bo van Nieuwenhuizen ${ }^{1}$ - Ulrike Gehring ${ }^{4}$ Annemieke M. W. Spijkerman ${ }^{1}$ • \\ Henriëtte A. Smit ${ }^{2}$
}

Received: 8 December 2015 / Accepted: 22 April 2016/Published online: 30 May 2016

(C) Springer-Verlag Berlin Heidelberg 2016

\begin{abstract}
Aims/hypothesis Despite the overlap in occurrence of cardiovascular disease (CVD) and type 2 diabetes and their risk factors, family history of these diseases has not yet been investigated simultaneously in relation to cardiometabolic markers in offspring. We examined how a family history of CVD and/or diabetes relates to cardiometabolic markers in offspring, and to what extent these diseases independently contribute to cardiometabolic markers.

Methods We used data from 1,374 12-year-old children and their parents participating in a birth cohort study in the Netherlands. Family history of CVD (myocardial infarction $[\mathrm{MI}]$ and stroke) and diabetes were reported by the parents. Children were classified as 'no', 'moderate' or 'strong' family history, based on early/late onset of disease in parents and grandparents. Cardiometabolic markers were measured at
\end{abstract}

Electronic supplementary material The online version of this article (doi:10.1007/s00125-016-3988-2) contains peer-reviewed but unedited supplementary material, which is available to authorised users.

Alet H. Wijga

alet.wijga@rivm.nl

1 Center for Nutrition, Prevention, and Health Services, National Institute for Public Health and the Environment, PO Box 1, 3720 BA Bilthoven, the Netherlands

2 Julius Center for Health Sciences and Primary Care, University Medical Center Utrecht, Utrecht, the Netherlands

3 University of Groningen, UMCG, Department of Pediatric Pulmonology and Pediatric Allergology, Beatrix Children's Hospital, GRIAC Research Institute, Groningen, the Netherlands

4 Institute for Risk Assessment Sciences (IRAS), Division of Environmental Epidemiology, Utrecht University, Utrecht, the Netherlands
12 years of age: waist circumference, cholesterol, blood pressure and $\mathrm{HbA}_{1 \mathrm{c}}$.

Results Compared with those with no family history, children with a strong family history of MI and/or stroke and/or diabetes $(29 \%$ of the study population) had $0.13 \mathrm{mmol} / 1$ higher total cholesterol (TC) $(95 \%$ CI $0.03,0.23)$ and 0.18 higher TC/ HDL-cholesterol (HDLC) ratio ( $95 \%$ CI $0.04,0.32$ ). A strong family history of MI or diabetes was independently associated with unfavourable cardiometabolic markers specific to those diseases. These associations remained after adjusting for BMI. Children with a moderate family history had no unfavourable cardiometabolic markers.

Conclusions/interpretation One-third of the children had a strong family history of CVD and/or diabetes. These children had higher TC levels and TC/HDLC ratios than children with no family history. A strong family history of MI or diabetes was independently associated with unfavourable cardiometabolic markers specific to those diseases.

Keywords Cardiovascular disease $\cdot$ Cholesterol $\cdot$ Diabetes . Family history $\cdot$ Paediatrics

$\begin{array}{ll}\text { Abbreviations } \\ \text { CVD } & \text { Cardiovascular disease } \\ \text { HDLC } & \text { HDL-cholesterol } \\ \text { PIAMA } & \text { Prevention and Incidence of Asthma and Mite } \\ & \text { Allergy } \\ \text { TC } & \text { Total cholesterol }\end{array}$

\section{Introduction}

Family history reflects genetic susceptibility as well as environmental and lifestyle characteristics shared within families, 
e.g. socioeconomic position and health behaviours [1]. The association of cardiovascular disease (CVD) in first- or second-degree relatives with the presence of risk factors for atherosclerosis, such as high cholesterol and BP, in children has been described $[2,3]$. Other studies showed that familial aggregation of type 2 diabetes also relates to the presence of cardiometabolic abnormalities in children [4-8]. CVD and type 2 diabetes often co-occur [3, 9, 10] and share risk factors such as hypertension, overweight, unhealthy diet and lack of physical activity. However, previous studies assessing cardiometabolic markers in children lacked data on family history of both CVD and diabetes, and it is unclear whether CVD and diabetes history are independently associated with cardiometabolic markers in children.

Lifestyle modification may reduce the risk of both CVD and type 2 diabetes [11-14]. Individuals and families with a history of these diseases may be more motivated to change their lifestyle because they are more aware of their increased risk for future disease [15]. Therefore, clarifying the cardiometabolic risk in children with a family history of CVD and/or diabetes is important for families at increased risk for future disease. Furthermore, when assessing associations of family history with children's cardiometabolic markers, few studies have accounted for the number of affected relatives, or have used a broader definition than early-onset disease to indicate a positive family history. In the current study, we examined differences in cardiometabolic markers among children with no family history, a moderate or a strong family history of CVD (myocardial infarction [MI] and stroke) and/or diabetes, in a contemporary Dutch population.

\section{Methods}

We used data from a population-based Dutch birth cohort study, the Prevention and Incidence of Asthma and Mite Allergy (PIAMA) study, with prenatal inclusion of 3,963 children in 1996/1997. A detailed description of the study design has been published previously [16]. At age 11 years, 3,541 children (89.4\%) were still in the study. Of those children, 3,202 were invited for a clinical assessment at age 12 years, and 1,511 participated (47.2\%). Around age 14 years, parents completed questionnaires including items on family history of MI, stroke and diabetes. The study population for the current study consisted of 1,374 children (704 girls, 670 boys) who had parental reports on family history and had had a clinical assessment at age 12 years. Children diagnosed with diabetes mellitus were excluded $(n=5)$. The study protocol was approved by the medical ethics committees of the participating institutes. All parents gave written informed consent for participation in the PIAMA birth cohort and separately for the clinical assessment; additionally, children themselves gave written informed consent for the clinical assessment.
Classification of family history Parents reported history of MI, stroke and diabetes for the biological parents and grandparents of the child, and age at onset. Response categories for each disease history were 'yes', 'no' and 'unknown'. To define the severity of family history, we classified children into three categories depending on the number of affected relatives, age at onset and degree of kinship to the child. We did this separately for MI, stroke, and diabetes. Children with no affected parents and grandparents were classified as 'no family history'. Children with one or two grandparents with late disease onset were classified as 'moderate family history'. Children with at least one affected parent or at least one grandparent with early disease onset or three or four grandparents with late disease onset were classified as 'strong family history'. Further subdivision between parents and grandparents led to small numbers in each category and therefore was not feasible. Classification for family history of CVD and/or diabetes followed classification for individual disease. Thus, children classified as 'strong family history' for at least one of MI, stroke or diabetes were classified as 'strong family history of CVD and/or diabetes'; the remaining children were classified as 'moderate' (when they were classified as such for at least one of MI, stroke or diabetes) or 'no' family history.

Early onset was defined as $<55$ years in grandfathers and $<65$ years in grandmothers for MI and stroke, in agreement with the 2011 integrated guidelines for cardiovascular health and risk reduction in youth by the American National Heart, Lung, and Blood Institute (NHLBI) Expert Panel [17]. For diabetes, early onset was before 50 years in grandfathers and grandmothers, a cut-off used in previous studies [18, 19].

The questionnaire inquired about history of diabetes, but not type 2 diabetes explicitly. A small proportion (12/693, 1.7\%) of all relatives with diabetes developed the disease before age 20 years; these were likely to have type 1 diabetes. We classified these relatives as not having diabetes, allowing us to interpret the results for children with a moderate or strong family history of diabetes as history of type 2 diabetes.

Electronic supplementary material (ESM) 1 provides insight into the prevalence of MI, stroke and diabetes for the study population, by disease and by family member. The prevalence of MI, stroke and diabetes in PIAMA parents was comparable with rates in the general (age-matched) Dutch population (see ESM 2). We could not compare disease prevalence in grandparents with that in the Dutch population because the ages of the grandparents were unknown.

Overall, $15 \%(n=208)$ of children had one or more unknown or missing items of family history. Missing values mostly concerned presence of disease $(n=154)$ and sometimes the age at disease onset $(n=39)$ or both $(n=15)$. The proportion of values reported as unknown or missing, relative to the total number of family members (six per child), was small for each disease: $2.5 \%$ for $\mathrm{MI} ; 2.3 \%$ for stroke; and $2.6 \%$ for diabetes. We classified relatives with missing age 
at onset for CVD or diabetes as late onset, to avoid misclassifying those with late onset as being in the highest risk category. If a specific disease in a specific relative was missing or 'unknown', we categorised this relative as not having that disease, as this was most likely considering the young age of the children and their parents. Otherwise, excluding the entire family history for this child would lead to loss of information. In addition, it reflects the real-world situation: people may not always be aware of diseases running in their (extended) families. We addressed this in a sensitivity analysis (see Statistical methods and ESM 3).

\section{Assessment of anthropometry and cardiometabolic} markers Clinical assessments at age 12 years were performed by trained staff during home visits according to standardised protocols. Height, weight and waist circumference were measured while children were wearing underwear. BMI $\left(\mathrm{kg} / \mathrm{m}^{2}\right)$ was used in the analyses as age- and sex-specific SD scores ( $z$ scores) using the reference growth curves of the fourth Dutch nationwide growth study carried out in 1997 [20]. Overweight (including obesity) was defined based using international defined cut-off points [21]. Waist circumference was measured twice and the mean of the two measurements was used in analyses.

Systolic and diastolic BP were measured according to the recommendations of the American Heart Association Council on High Blood Pressure Research [22]. BP readings were obtained from the non-dominant upper arm using an Omron M6 monitor while the child was seated. The first measurement was taken after $\geq 5$ min of rest, without talking. Depending on arm circumference, a $17-22 \mathrm{~cm}$ or $22-32 \mathrm{~cm}$ cuff was used. $\mathrm{BP}$ was measured at least twice with $5 \mathrm{~min}$ intervals. If two consecutive measures differed by $>5 \mathrm{mmHg}$, another measurement was taken. The means of (two or three) systolic and diastolic measurements were used in analyses.

Blood was drawn for measurement of cholesterol and $\mathrm{HbA}_{1 \mathrm{c}}$. Serum levels of total cholesterol (TC) and HDLcholesterol (HDLC) were determined enzymatically using Roche automated clinical chemistry analysers (Roche Diagnostics, Indianapolis, IN, USA). The ratio of TC and HDLC was calculated (TC/HDLC ratio). For analysis of $\mathrm{HbA}_{1 \mathrm{c}}$, erythrocytes from blood samples were stored, a $5 \mu \mathrm{l}$ cell mass was lysed and $\mathrm{HbA}_{1 \mathrm{c}}$ was measured by ionexchange chromatography using the Adams A1c HA-8160 HPLC auto analyser (Menarini Diagnostics Benelux, Valkenswaard, the Netherlands). This analyser was standardised on DCCT standards.

Other characteristics Characteristics used to describe the study population were: the child's sex, ethnicity, age, pubertal development; and parental age, education and BMI. Ethnicity was based on the country of birth of the child's parents, and was categorised as Dutch, non-Dutch western and non-western. Pubertal development (puberty development scale, 1-4) [23] was reported by the child at age 11 years and used as a continuous variable in the analysis. The mother's and father's educational levels were categorised as low (primary school, lower vocational or lower secondary education), intermediate (intermediate vocational education or intermediate/higher secondary education) or high (higher vocational education and university). The mother's and father's BMI were calculated from reported weight and height when the child was 14 years old and were categorised as overweight (BMI $\geq 25 \mathrm{~kg} / \mathrm{m}^{2}$ ) or normal weight $\left(\mathrm{BMI}<25 \mathrm{~kg} / \mathrm{m}^{2}\right)$.

Statistical methods Differences in cardiometabolic markers in children with moderate or strong family history were assessed by multiple linear regression analyses, treating no family history as reference. Across the categories, $p$ values for trend were estimated by treating the categorical variables as continuous variables in the model. We adjusted for child's sex, age at clinical assessment, ethnicity, height, pubertal development, maternal and paternal education and maternal and paternal age in the first adjusted model. These confounders were selected based on prior knowledge and their associations with the outcome of interest. Parents and grandparents who were older at the time of family history assessment were more likely to have developed the disease. We adjusted for this by including maternal and paternal age in the regression models, considering these as a proxy for grandparental age. Analyses with BP were additionally adjusted for cuff size. In the second model, we added maternal and paternal BMI to investigate whether associations could be explained by BMI levels shared within families. In the third model, we further added the child's BMI (measured at age 12 years). We investigated whether family history of MI, stroke or diabetes was independently associated with cardiometabolic markers by mutually adjusting for the other two diseases. Differences by sex have been observed in the association between family history and offspring cardiometabolic markers [24]. We investigated this by including interaction terms of sex with family history categories in the regression models. We conducted two sensitivity analyses to determine the robustness of the associations (see ESM 3 and 4). We used SAS version 9.3 for all analyses (SAS Institute, Cary, NC, USA).

\section{Results}

History of parental MI was present for $1.3 \%$ of the children, $0.8 \%$ had a history of parental stroke and $3.5 \%$ had a history of parental diabetes. More children had grandfathers with MI or stroke than grandmothers ( $43 \%$ vs $11 \%$ for MI and $19 \%$ vs $14 \%$ for stroke, respectively), whereas history of diabetes was 
similar in grandfathers and grandmothers (24\% vs $23 \%)$ (ESM 1).

Based on family history of individual diseases, $17 \%$ of the children had a strong family history of MI, $8 \%$ of stroke and $10 \%$ of diabetes (Table 1). Considering a combination of family history of MI, and/or stroke and/or diabetes, $29 \%$ of the children $(n=401)$ had a strong family history. Of these children, $84 \%$ had a strong family history of one disease only: $43 \%(n=173)$ of MI only; $17 \%(n=69)$ of stroke only; and $24 \%(n=96)$ of diabetes only (data not shown). Children with a strong family history of CVD and/or diabetes were more often overweight, of non-western ethnicity and had parents with a lower education and with a higher BMI compared with children with no family history (Table 2 ). There were no large differences in age, sex or pubertal development.

Overall, children with a moderate family history of CVD and/or diabetes had no unfavourable cardiometabolic markers whereas children with a strong family history did when compared with children with no family history (Table 3). The $p$ values for trend from moderate to strong family history were significant only for the associations hereafter (Table 3). Children with a strong family history of MI had $0.12 \mathrm{mmol} / \mathrm{l}$ higher TC (95\% CI 0.01, 0.23), $0.05 \mathrm{mmol} / \mathrm{l}$ lower HDLC $(95 \% \mathrm{CI}-0.10$, $-0.003)$ and 0.24 higher TC/HDLC ratio $(95 \% \mathrm{CI} 0.09,0.39)$ compared with those with no family history, after adjustment for confounders (Table 4). Children with a strong family history of

Table 1 Categories of family history of MI, stroke and diabetes and number of children in each category

\begin{tabular}{llr}
\hline Disease & Children & \\
\cline { 2 - 3 } & $n$ & $\%$ \\
\hline MI $^{\mathrm{a}}$ & & \\
No family history & 760 & 55.3 \\
$\quad$ Moderate family history & 387 & 28.2 \\
$\quad$ Strong family history & 227 & 16.5 \\
Stroke & & \\
No family history & 968 & 70.5 \\
Moderate family history & 300 & 21.8 \\
Strong family history & 106 & 7.7 \\
Diabetes & & \\
No family history & & 61.4 \\
Moderate family history & 844 & 28.9 \\
$\quad$ Strong family history & 397 & 9.7 \\
CVD $^{\mathrm{b}}$ and/or diabetes & 133 & 27.3 \\
$\quad$ No family history & & 43.5 \\
Moderate family history & 375 & 29.2 \\
Strong family history & 598 & \\
\hline
\end{tabular}

${ }^{a}$ Family history of a single disease did not exclude having a family history for another disease

${ }^{\mathrm{b}} \mathrm{MI}$ and/or stroke diabetes had a $2.25 \mathrm{~cm}$ larger waist circumference $(95 \% \mathrm{CI}$ $1.08,3.41), 0.20 \mathrm{mmol} / \mathrm{l}$ higher TC $(95 \%$ CI $0.07,0.34), 0.22$ higher TC/HDLC ratio $(95 \% \mathrm{CI} 0.03,0.40)$ and $0.57 \mathrm{mmol} / \mathrm{mol}$ higher $\mathrm{HbA}_{1 \mathrm{c}}(95 \% \mathrm{CI} 0.06,1.09)$. A strong family history of stroke was not associated with cardiometabolic markers. Children with a strong family history of CVD and/or diabetes compared with those with no family history had $0.13 \mathrm{mmol} / \mathrm{l}$ higher TC $(95 \%$ CI $0.03,0.23)$ and 0.18 higher TC/HDLC ratio (95\% CI 0.04, 0.32). For most of the cardiometabolic markers, adjustment for BMI of the parents and subsequent adjustment for BMI of the child hardly changed the effect estimates in children with a strong family history (Table 4). Effect estimates and interpretation of the results did not change after adjusting for waist circumference of the child instead of BMI (data not shown). The associations remained when mutually adjusting for family history of the other diseases (Table 5); strong family histories of MI and diabetes were independently associated with 0.11 and $0.18 \mathrm{mmol} / \mathrm{l}$ higher TC, respectively.

Associations of family history of CVD/diabetes with cardiometabolic markers were similar in boys and girls ( $p$ values for interaction $>0.15$ ). We therefore show results for boys and girls combined. Sensitivity analyses indicated that associations were robust and not affected by missing data or by reporting of disease history for the family in-law (ESM 3 and 4).

\section{Discussion}

One-third of the 12-year-olds in our study had a strong family history of CVD and/or diabetes, and these children had higher TC levels and TC/HDLC ratios than children with no family history. Compared with family history of CVD and/or diabetes, a strong family history of a single disease was present in fewer children, but showed stronger associations with diseasespecific cardiometabolic markers. Family history of MI may be most relevant for children's cholesterol levels (HDL, TC and TC/HDLC ratio), whereas family history of diabetes may be relevant for children's waist circumference and $\mathrm{HbA}_{1 \mathrm{c}}$, in addition to cholesterol levels. Importantly, the associations for individual diseases were independent of family history of the other diseases. Children with a moderate family history had no unfavourable cardiometabolic markers.

As far as we are aware, only three studies have previously investigated family history of both CVD and diabetes and cardiometabolic outcomes in children from the general population [24-26]. One study investigated cardiometabolic markers in the child as predictors of parents' subsequent CVD and diabetes; therefore, our results are not directly comparable [25]. The other two studies were conducted two decades ago within the Bogalusa Heart Study. They lacked the disease history of grandparents and age of the parents, and therefore were not able to categorise individuals into groups with no, 
Table 2 Characteristics of the study population within categories of family history of CVD and/or diabetes

\begin{tabular}{|c|c|c|c|c|c|c|}
\hline \multirow[t]{2}{*}{ Characteristic } & \multicolumn{2}{|c|}{ No family history $(n=375)$} & \multicolumn{2}{|c|}{ Moderate family history $(n=598)$} & \multicolumn{2}{|c|}{ Strong family history $(n=40$} \\
\hline & $n$ & Mean (SD) or \% & $n$ & Mean (SD) or \% & $n$ & Mean (SD) or \% \\
\hline \multicolumn{7}{|l|}{ Child's characteristics } \\
\hline Sex (boy) & 375 & 49.1 & 598 & 49.0 & 401 & 48.1 \\
\hline Dutch & 371 & 93.3 & 590 & 92.2 & 395 & 91.4 \\
\hline Non-Dutch western ethnicity & 371 & 2.4 & 590 & 4.8 & 395 & 3.0 \\
\hline Non-western ethnicity & 371 & 4.3 & 590 & 3.1 & 395 & 5.6 \\
\hline Age at clinical assessment (years) & 375 & $12.7(0.4)$ & 598 & $12.7(0.4)$ & 401 & $12.7(0.4)$ \\
\hline Puberty development scale at age 11 years & 371 & $1.5(0.5)$ & 585 & $1.5(0.5)$ & 394 & $1.6(0.5)$ \\
\hline \multicolumn{7}{|l|}{ Parental characteristics } \\
\hline \multicolumn{7}{|l|}{ Mother's education } \\
\hline Low & 375 & $14.4^{*}$ & 597 & $16.6^{*}$ & 400 & $19.0 *$ \\
\hline High & 375 & $47.5^{*}$ & 597 & $44.7^{*}$ & 400 & $33.8^{*}$ \\
\hline \multicolumn{7}{|l|}{ Father's education } \\
\hline Low & 372 & $15.6^{*}$ & 596 & $17.8^{*}$ & 395 & $27.3^{*}$ \\
\hline High & 372 & $55.4^{*}$ & 596 & $48.0^{*}$ & 395 & $38.5^{*}$ \\
\hline Mother's BMI $\left(\mathrm{kg} / \mathrm{m}^{2}\right)$ at child's age 14 & 369 & $24.3(3.4)^{*}$ & 581 & $24.5(3.8)^{*}$ & 392 & $25.0(4.3)^{*}$ \\
\hline Father's BMI $\left(\mathrm{kg} / \mathrm{m}^{2}\right)$ at child's age 14 & 358 & $25.5(3.1)^{*}$ & 569 & $25.8(3.3)^{*}$ & 389 & $26.3(3.5)^{*}$ \\
\hline Mother overweight/obese at child's age 14 & 369 & 32.0 & 581 & 38.2 & 392 & 38.5 \\
\hline Father overweight/obese at child's age 14 & 358 & $50.8^{*}$ & 569 & $53.6^{*}$ & 389 & $59.6^{*}$ \\
\hline \multicolumn{7}{|l|}{ Family history reported by } \\
\hline Mother & 374 & 82.4 & 597 & 85.1 & 401 & 87.8 \\
\hline Father & 374 & 9.6 & 597 & 5.4 & 401 & 4.5 \\
\hline Both parents together & 374 & 7.5 & 597 & 9.4 & 401 & 7.5 \\
\hline Mother's age at time of reporting family history & 369 & $45.9(3.6)^{*}$ & 594 & $46.6(3.7)^{*}$ & 397 & $45.9(3.8)^{*}$ \\
\hline Father's age at time of reporting family history & 365 & $47.9(4.6)^{*}$ & 589 & $48.8(4.5)^{*}$ & 395 & $48.6(5.0)^{*}$ \\
\hline \multicolumn{7}{|l|}{ Child's adiposity at 12 years of age } \\
\hline Child overweight/obese & 375 & 11.7 & 597 & 12.7 & 400 & 13.5 \\
\hline BMI ( $z$ score $)$ & 375 & $0.1(1.0)$ & 597 & $0.1(1.1)$ & 400 & $0.2(1.1)$ \\
\hline \multicolumn{7}{|l|}{ Cardiometabolic markers at 12 years of age } \\
\hline Waist circumference (cm) & 375 & $66.0(6.3)$ & 595 & $66.3(6.5)$ & 399 & $67.2(7.4)$ \\
\hline $\mathrm{TC}(\mathrm{mmol} / \mathrm{l})$ & 319 & $4.0(0.7)^{*}$ & 513 & $4.0(0.6)^{*}$ & 340 & $4.2(0.7)^{*}$ \\
\hline HDLC (mmol/l) & 319 & $1.4(0.3)$ & 513 & $1.4(0.3)$ & 340 & $1.3(0.3)$ \\
\hline Total/HDLC ratio & 319 & $3.1(0.8)^{*}$ & 513 & $3.1(0.9)^{*}$ & 340 & $3.3(0.9)^{*}$ \\
\hline Systolic BP (mmHg) & 352 & $115.0(9.2)$ & 566 & $114.8(9.4)$ & 384 & $114.6(8.9)$ \\
\hline Diastolic BP (mmHg) & 352 & $66.7(6.2)$ & 566 & $66.6(6.6)$ & 384 & $66.9(6.5)$ \\
\hline $\mathrm{HbA}_{1 \mathrm{c}}(\mathrm{mmol} / \mathrm{mol})$ & 313 & $32.3(2.5)$ & 509 & $32.3(2.4)$ & 335 & $32.6(2.6)$ \\
\hline $\mathrm{HbA}_{1 \mathrm{c}}(\%)$ & 313 & 5.1 & 509 & 5.1 & 335 & 5.1 \\
\hline
\end{tabular}

CVD includes MI and/or stroke

${ }^{*} p<0.05$ for difference in characteristics between the three family history categories, generated by ANOVA for normally distributed data, KruskalWallis test for non-normally distributed data and $\chi^{2}$ test for proportions

moderate or strong family history. Bao et al observed that, in adolescents aged 11-17 years, parental MI was related to higher systolic BP and insulin, parental stroke was not related to cardiometabolic markers and parental diabetes was related to higher systolic BP and glucose levels [24]. Shear et al further specified that among children aged 5-7 years, those with one parent with diabetes plus another parent with CVD or diabetes had the highest lipid levels [26]. Our study is the first to investigate both diabetes and cardiovascular disease history in two generations. Our findings add to the previous findings that in 12-year-old children from a contemporary cohort, history of MI and diabetes in parents and grandparents may be a relevant and important risk 
Table 3 Differences in levels of cardiometabolic markers for children with a moderate or strong family history compared with children with no family history $(n=1,374)$

\begin{tabular}{|c|c|c|c|c|c|c|c|}
\hline Disease & $\begin{array}{c}\text { Waist } \\
\text { circumference }(\mathrm{cm})\end{array}$ & $\mathrm{TC}(\mathrm{mmol} / \mathrm{l})$ & $\operatorname{HDLC}(\mathrm{mmol} / \mathrm{l})$ & TC/HDLC ratio & $\begin{array}{l}\text { Systolic BP } \\
(\mathrm{mmHg})^{\mathrm{a}}\end{array}$ & $\begin{array}{l}\text { Diastolic BP } \\
(\mathrm{mmHg})^{\mathrm{b}}\end{array}$ & $\begin{array}{c}\mathrm{HbA}_{1 \mathrm{c}} \\
(\mathrm{mmol} / \mathrm{mol})\end{array}$ \\
\hline \multicolumn{8}{|l|}{ MI } \\
\hline $\begin{array}{l}\text { Moderate family } \\
\text { history }\end{array}$ & $\begin{array}{c}0.13 \\
(-0.65,0.90)\end{array}$ & $\begin{array}{c}0.06 \\
(-0.03,0.15)\end{array}$ & $\begin{array}{c}-0.02 \\
(-0.06,0.02)\end{array}$ & $\begin{array}{c}0.11 \\
(-0.01,0.24)\end{array}$ & $\begin{array}{c}-0.15 \\
(-1.30,1.00)\end{array}$ & $\begin{array}{c}0.69 \\
(-0.15,1.53)\end{array}$ & $\begin{array}{c}0.08 \\
(-0.26,0.41)\end{array}$ \\
\hline $\begin{array}{l}\text { Strong family } \\
\text { history }\end{array}$ & $\begin{array}{c}0.55 \\
(-0.39,1.49)\end{array}$ & $\begin{array}{c}0.12 \\
(0.01,0.23)^{* \dagger}\end{array}$ & $\begin{array}{c}-0.05 \\
(-0.10,-0.003)^{* \dagger}\end{array}$ & $\begin{array}{c}0.24 \\
(0.09,0.39)^{* \dagger}\end{array}$ & $\begin{array}{c}-1.13 \\
(-2.52,0.26)\end{array}$ & $\begin{array}{c}0.17 \\
(-0.84,1.19)\end{array}$ & $\begin{array}{c}0.29 \\
(-0.11,0.70)\end{array}$ \\
\hline \multicolumn{8}{|l|}{ Stroke } \\
\hline $\begin{array}{l}\text { Moderate family } \\
\text { history }\end{array}$ & $\begin{array}{c}-0.30 \\
(-1.12,0.52)\end{array}$ & $\begin{array}{c}-0.03 \\
(-0.12,0.07)\end{array}$ & $\begin{array}{c}-0.03 \\
(-0.07,0.02)\end{array}$ & $\begin{array}{c}0.001 \\
(-0.13,0.13)\end{array}$ & $\begin{array}{c}1.30 \\
(0.09,2.51)^{*}\end{array}$ & $\begin{array}{c}0.27 \\
(-0.61,1.15)\end{array}$ & $\begin{array}{c}-0.41 \\
(-0.77,-0.05)^{*}\end{array}$ \\
\hline $\begin{array}{l}\text { Strong family } \\
\text { history }\end{array}$ & $\begin{array}{c}-0.25 \\
(-1.51,1.00)\end{array}$ & $\begin{array}{c}-0.03 \\
(-0.17,0.11)\end{array}$ & $\begin{array}{c}-0.05 \\
(-0.12,0.01)\end{array}$ & $\begin{array}{c}0.10 \\
(-0.09,0.30)\end{array}$ & $\begin{array}{c}-0.41 \\
(-2.27,1.44)\end{array}$ & $\begin{array}{c}-0.42 \\
(-1.77,0.94)\end{array}$ & $\begin{array}{c}-0.05 \\
(-0.59,0.49)\end{array}$ \\
\hline \multicolumn{8}{|l|}{ Diabetes } \\
\hline $\begin{array}{l}\text { Moderate family } \\
\text { history }\end{array}$ & $\begin{array}{c}0.52 \\
(-0.23,1.27)\end{array}$ & $\begin{array}{c}-0.01 \\
(-0.10,0.07)\end{array}$ & $\begin{array}{c}-0.01 \\
(-0.05,0.03)\end{array}$ & $\begin{array}{c}0.05 \\
(-0.06,0.17)\end{array}$ & $\begin{array}{c}-0.71 \\
(-1.82,0.40)\end{array}$ & $\begin{array}{c}-0.73 \\
(-1.54,0.08)\end{array}$ & $\begin{array}{c}0.12 \\
(-0.20,0.44)\end{array}$ \\
\hline $\begin{array}{l}\text { Strong family } \\
\text { history }\end{array}$ & $\begin{array}{c}2.25 \\
(1.08,3.41)^{* \dagger}\end{array}$ & $\begin{array}{c}0.20 \\
(0.07,0.34)^{* \dagger}\end{array}$ & $\begin{array}{c}-0.004 \\
(-0.07,0.05)\end{array}$ & $\begin{array}{c}0.22 \\
(0.03,0.40)^{* \dagger}\end{array}$ & $\begin{array}{c}0.89 \\
(-0.82,2.61)\end{array}$ & $\begin{array}{c}0.59 \\
(-0.66,1.84)\end{array}$ & $\begin{array}{c}0.57 \\
(0.06,1.09)^{* \dagger}\end{array}$ \\
\hline \multicolumn{8}{|l|}{$\mathrm{CVD}^{\mathrm{b}}$ and/or diabetes } \\
\hline $\begin{array}{l}\text { Moderate family } \\
\text { history }\end{array}$ & $\begin{array}{c}-0.07 \\
(-0.88,0.74)\end{array}$ & $\begin{array}{c}0.02 \\
(-0.08,0.11)\end{array}$ & $\begin{array}{c}0.003 \\
(-0.04,0.05)\end{array}$ & $\begin{array}{c}0.001 \\
(-0.13,0.13)\end{array}$ & $\begin{array}{c}0.18 \\
(-1.03,1.38)\end{array}$ & $\begin{array}{c}0.03 \\
(-0.85,0.92)\end{array}$ & $\begin{array}{c}-0.06 \\
(-0.42,0.29)\end{array}$ \\
\hline $\begin{array}{l}\text { Strong family } \\
\text { history }\end{array}$ & $\begin{array}{c}0.64 \\
(-0.25,1.53)\end{array}$ & $\begin{array}{c}0.13 \\
(0.03,0.23)^{* \dagger}\end{array}$ & $\begin{array}{c}-0.03 \\
(-0.07,0.02)\end{array}$ & $\begin{array}{c}0.18 \\
(0.04,0.32)^{*} \dagger\end{array}$ & $\begin{array}{c}-0.19 \\
(-1.51,1.13)\end{array}$ & $\begin{array}{c}0.11 \\
(-0.86,1.07)\end{array}$ & $\begin{array}{c}0.22 \\
(-0.16,0.61)\end{array}$ \\
\hline
\end{tabular}

Differences are $\beta(95 \% \mathrm{CI})$, adjusted for child's sex, age, ethnicity, height, pubertal development, maternal and paternal education and maternal and paternal age

${ }^{a}$ Additionally adjusted for cuff size

${ }^{\mathrm{b}} \mathrm{MI}$ and/or stroke

${ }^{*} p<0.05$ vs children with no family history

${ }^{\dagger} p$ for trend $<0.05$ across family history categories

Table 4 Differences in levels of cardiometabolic markers for children with a strong family history compared with children with no family history

\begin{tabular}{|c|c|c|c|c|c|c|c|}
\hline & $\begin{array}{c}\text { Waist } \\
\text { circumference } \\
(\mathrm{cm})\end{array}$ & $\mathrm{TC}(\mathrm{mmol} / \mathrm{l})$ & HDLC (mmol/l) & $\begin{array}{c}\mathrm{TC} / \mathrm{HDLC} \\
\text { ratio }\end{array}$ & $\begin{array}{l}\text { Systolic BP } \\
(\mathrm{mmHg})^{\mathrm{a}}\end{array}$ & $\begin{array}{l}\text { Diastolic BP } \\
(\mathrm{mmHg})^{\mathrm{a}}\end{array}$ & $\begin{array}{c}\mathrm{HbA}_{1 \mathrm{c}} \\
(\mathrm{mmol} / \mathrm{mol})\end{array}$ \\
\hline \multicolumn{8}{|l|}{ MI } \\
\hline Adjusted & $0.55(-0.39,1.49)$ & $0.12(0.01,0.23)^{*}$ & $-0.05(-0.10,-0.003)^{*}$ & $0.24(0.09,0.39)^{*}$ & $-1.13(-2.52,0.26)$ & $0.17(-0.84,1.19)$ & $0.29(-0.11,0.70)$ \\
\hline $\begin{array}{l}+ \text { BMI } \\
\text { parents }\end{array}$ & $0.23(-0.68,1.14)$ & $0.12(0.01,0.23)^{*}$ & $-0.05(-0.10,-0.002)^{*}$ & $0.24(0.09,0.39)^{*}$ & $-1.18(-2.57,0.22)$ & $0.13(-0.90,1.16)$ & $0.39(-0.02,0.80)$ \\
\hline + BMI child & - & $0.12(0.005,0.23)^{*}$ & $-0.05(-0.10,0.0003)$ & $0.23(0.08,0.37)^{*}$ & $-1.33(-2.71,0.05)$ & $0.04(-0.98,1.06)$ & $0.39(-0.02,0.80)$ \\
\hline \multicolumn{8}{|c|}{ 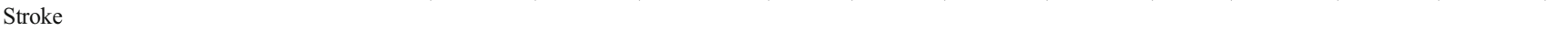 } \\
\hline Adjusted & $-0.25(-1.51,1.00)$ & $-0.03(-0.17,0.11)$ & $-0.05(-0.12,0.01)$ & $0.10(-0.09,0.30)$ & $-0.41(-2.27,1.44)$ & $-0.42(-1.77,0.94)$ & $-0.05(-0.59,0.49)$ \\
\hline $\begin{array}{l}+ \text { BMI } \\
\text { parents }\end{array}$ & $-0.19(-1.40,1.02)$ & $-0.02(-0.17,0.12)$ & $-0.06(-0.12,0.01)$ & $0.13(-0.07,0.33)$ & $-0.53(-2.38,1.33)$ & $-0.47(-1.84,0.90)$ & $-0.01(-0.56,0.53)$ \\
\hline + BMI child & - & $-0.02(-0.16,0.13)$ & $-0.05(-0.12,0.01)$ & $0.12(-0.07,0.31)$ & $-0.35(-2.18,1.49)$ & $-0.35(-1.70,1.00)$ & $-0.02(-0.56,0.53)$ \\
\hline \multicolumn{8}{|l|}{ Diabetes } \\
\hline Adjusted & $2.25(1.08,3.41)^{*}$ & $0.20(0.07,0.34)^{*}$ & $-0.004(-0.07,0.05)$ & $0.22(0.03,0.40)^{*}$ & $0.89(-0.82,2.61)$ & $0.59(-0.66,1.84)$ & $0.57(0.06,1.09)^{*}$ \\
\hline $\begin{array}{l}+ \text { BMI } \\
\text { parents }\end{array}$ & $1.42(0.28,2.56)^{*}$ & $0.21(0.07,0.34)^{*}$ & $-0.003(-0.07,0.06)$ & $0.20(0.01,0.39)^{*}$ & $0.50(-1.24,2.23)$ & $0.56(-0.72,1.84)$ & $0.54(0.01,1.06)$ \\
\hline & \multicolumn{6}{|c|}{$\mathrm{CVD}^{\mathrm{b}}$ and/or diabetes } & $0.54(0.01,1.07)$ \\
\hline Adjusted & $0.64(-0.25,1.53)$ & $0.13(0.03,0.23) *$ & $-0.03(-0.07,0.02)$ & $0.18(0.04,0.32)^{*}$ & $-0.19(-1.51,1.13)$ & $0.11(-0.8$ & $0.22(-0.16,0.61)$ \\
\hline $\begin{array}{l}+ \text { BMI } \\
\text { parents }\end{array}$ & $0.24(-0.63,1.10)$ & $0.14(0.03,0.24)^{*}$ & $-0.03(-0.07,0.02)$ & $0.18(0.04,0.33)^{*}$ & $-0.42(-1.75,0.92)$ & $0.04(-0.94,1.03)$ & $0.21(-0.18,0.61)$ \\
\hline + BMI child & - & $0.14(0.03,0.24)^{*}$ & $-0.02(-0.07,0.02)$ & $0.18(0.04,0.32)^{*}$ & $-0.45(-1.77,0.87)$ & $-0.002(-0.97,0.97)$ & $0.21(-0.18,0.61)$ \\
\hline
\end{tabular}

Differences are $\beta(95 \% \mathrm{CI})$

The adjusted model included child's sex, age, ethnicity, height, pubertal development, maternal and paternal education and maternal and paternal age. Subsequently, models additionally adjusted for maternal and paternal BMI; and child's BMI $z$ score at age 12 years (excluding child's height)

${ }^{\text {a }}$ Additionally adjusted for cuff size

${ }^{\mathrm{b}} \mathrm{MI}$ and/or stroke

${ }^{*} p<0.05$ vs children with no family history 
Table 5 Differences in levels of cardiometabolic markers for children with a strong family history compared with children with no family history, mutually adjusted for family history of the other diseases

\begin{tabular}{lccccccc}
\hline Disease & $\begin{array}{c}\text { Waist circumference } \\
(\mathrm{cm})\end{array}$ & $\mathrm{TC}(\mathrm{mmol} / \mathrm{l})$ & $\mathrm{HDLC}(\mathrm{mmol} / \mathrm{l})$ & $\mathrm{TC} / \mathrm{HDLC}$ ratio & $\begin{array}{c}\text { Systolic BP } \\
(\mathrm{mmHg})^{\mathrm{a}}\end{array}$ & $\begin{array}{c}\text { Diastolic BP } \\
(\mathrm{mmHg})^{\mathrm{a}}\end{array}$ & $\begin{array}{c}\mathrm{HbA} \\
(\mathrm{mmol} / \mathrm{mol})\end{array}$ \\
\hline MI & 0.44 & 0.11 & -0.05 & 0.22 & -1.18 & 0.23 & 0.26 \\
& $(-0.55,1.42)$ & $(0.003,0.22)$ & $(-0.10,0.002)$ & $(0.07,0.37)^{*}$ & $(-2.60,0.23)$ & $(-0.79,1.25)$ & $(-0.15,0.66)$ \\
Stroke & -0.49 & -0.03 & -0.04 & 0.08 & -0.34 & -0.37 & $(-0.09$ \\
& $(-1.80,0.83)$ & $(-0.17,0.12)$ & $(-0.11,0.02)$ & $(-0.12,0.28)$ & $(-2.23,1.56)$ & $(-1.73,0.99)$ & $(-0.63,0.46)$ \\
Diabetes & 2.40 & 0.18 & -0.01 & 0.19 & 1.14 & 0.55 & 0.53 \\
& $(1.17,3.63)^{*}$ & $(0.05,0.32)^{*}$ & $(-0.07,0.06)$ & $(0.001,0.37)$ & $(-0.61,2.88)$ & $(-0.70,1.80)$ & $(0.01,1.05)^{*}$ \\
\hline
\end{tabular}

Differences are $\beta(95 \% \mathrm{CI})$ and adjusted for child's sex, age, ethnicity, height, pubertal development, maternal and paternal education, and maternal and paternal age. The family history variables for MI, stroke and diabetes were combined in one model; estimates are thus mutually adjusted for family history of the other two diseases

${ }^{a}$ Additionally adjusted for cuff size

${ }^{*} p<0.05$ vs children with no family history

factor for unfavourable waist circumference, levels of cholesterol and $\mathrm{HbA}_{1 \mathrm{c}}$, and potentially for future cardiometabolic disease, largely independent of parental and child BMI.

In our study, stroke was not strongly associated with cardiometabolic markers. This is consistent with results from other studies in children [24, 26] and adults [27]. Although a family history of stroke has been associated with clinical CHD outcomes, such as heart attack, in adult studies, history of stroke is generally not associated with outcomes of subclinical atherosclerosis, such as the intermediate risk factors investigated in the current study. Bao et al noted that the predictive nature of stroke may also be limited by differences in the aetiological origin of different types of stroke, i.e. ischaemic or haemorrhagic [24]. Family history of CVD or diabetes was not associated with the child's BP in our study. The Bogalusa Heart Study showed that associations with BP may emerge at older ages than our population of 12-year-olds, particularly in children whose parents have hypertension [24].

A key strength of this study is the availability of extensive family history information for three different diseases, which allowed us to estimate the combined disease burden that runs within families and to show disease-specific associations. We obtained disease history and age at onset for parents as well as grandparents, which enabled us to define the family history burden in children more precisely. We adjusted for parental BMI and child BMI and showed that most associations were independent of these factors.

The limitations of this study include reliance on retrospective parent-reported family history. Although we could not validate reported history of diabetes and CVD with medical records, evidence suggests that family history of diabetes and major CVD events are reported fairly accurately, because they are serious, but not stigmatised, diseases with clear case definitions [3, 28]. Family history of diabetes may have been underreported because of under diagnosis [3], which may have led to underestimation of the true association. Mothers of the PIAMA children completed most questionnaires (85\%), which is likely to explain the higher number of unknowns and missing reports of disease cases in the fathers' lineage. However, the total percentage of missing responses and unknowns in reports of family history was small $(2-3 \%)$, and a systematic review and meta-analysis recently concluded that transmission of CVD risk is not different between fathers' and mothers' lineages [29]. This seems also true for diabetes [30]. In addition, when we restricted the main analysis to children who lived with both parents together, effect sizes hardly changed, indicating that potential misreporting by single parents did not affect the results. For these reasons, we do not expect that the higher proportion of missing family history reports in fathers' lineages will have biased the associations.

In the current study, a strong family history of CVD and/or diabetes was defined as at least one affected parent, at least one grandparent with early disease onset or three or four grandparents with late disease onset, but no gold standard exists for the definition of family history of disease [31, 32]. Compared with the most commonly used dichotomous score, our classification has important benefits as it accounts for number of relatives, age at onset and degree of kinship. A further advantage is our approach of investigating parents and grandparents, as this implies that the maximum family history 'score' was equal for all families (in contrast to other scores that may be higher or lower relative to the family size).

Our study lacked power to assess combinations of two or three diseases, e.g. a strong family history of either diabetes or CVD, and of both diabetes and CVD. The majority of the children had a strong family history of only one disease, thus the prevalence of a strong family history of diabetes and MI was only $2 \%$. It may be relevant for future studies to investigate a combined family history of CVD and diabetes, rather than single family history, in relation to the offspring's 
cardiometabolic markers. Such analyses would clarify whether the burden of two diseases combined is higher than the burden of single disease in the family.

The percentage of children with a strong family history in our study and the strengths of the associations we observed should not be interpreted in absolute terms. The incidence of type 2 diabetes and particularly of CVD increases with age, therefore future events in parents and grandparents are likely to reclassify children towards higher risk categories. This may affect the magnitude of the observed differences, which may be more pronounced with an increasing proportion of children with a strong family history. The associations, in particular with waist circumference and TC/HDLC ratio, were strong and the differences $(2.25 \mathrm{~cm}$ waist circumference and 0.22 TC/HDLC ratio for children with strong vs no family history of diabetes) may be considered clinically relevant [33, 34]. Cardiometabolic markers track over time from childhood to adulthood $[35,36]$. When measured in adolescence or early adulthood, cardiometabolic markers relate to adult carotid intima media thickness and cardiovascular disease [36, 37]. Therefore, children with subclinical elevated cardiometabolic markers are likely to be at risk for developing cardiovascular disease in adulthood.

Children with a strong family history of CVD and/or diabetes were more often overweight, had parents who were born in a non-western country, with a lower level of education and a higher BMI. Typically, these are priority groups for the prevention of overweight and cardiovascular disease, but also the groups that are not easily reached by preventive efforts. An awareness of a potentially increased risk for their children of diseases later in life that is associated with their own family disease history may increase families' motivation to follow healthy lifestyle guidelines [38]. Children of immigrants were under-represented in the PIAMA study, and we cannot exclude the possibility that different associations of family history of diabetes/CVD with offspring cardiometabolic markers would be observed for other ethnicities. Most associations persisted after adjusting for parental BMI, indicating that parental BMI as a proxy for shared lifestyle within families could not completely explain the associations between family history and child's cardiometabolic markers. Moreover, associations remained significant after additionally adjusting for child's BMI, indicating that even children with a healthy weight could be at risk for unfavourable levels of cardiometabolic markers if their parents or grandparents had MI or diabetes. Lifestyle factors may be on the pathway from family history to cardiometabolic markers in offspring, which is an important topic for further investigation. Future studies may particularly focus on lifestyle behaviours that are passed on from one generation to the next as these may account for (part of) the association of diabetes/CVD in multiple generations with cardiometabolic risk in the offspring.

\section{Conclusions}

A large proportion of children in our study had a strong family history of CVD and/or diabetes, with cholesterol levels that were significantly higher than the levels in children with no family history of disease. Children with a strong family history of MI or diabetes had unfavourable cardiometabolic markers that were specific to those diseases.

Acknowledgements The authors gratefully acknowledge the contribution of all participating children and parents or caregivers in the PIAMA study. We thank A. Wolse, M. Tewis and M. Oldenwening (IRAS, Utrecht, the Netherlands) for their contribution to the data collection and data management.

Funding The PIAMA study was funded by grants from: the Netherlands Organisation for Health Research and Development; the Netherlands Asthma Foundation; the Netherlands Ministry of Planning, Housing and the Environment; the Netherlands Ministry of Health, Welfare and Sport; and the National Institute for Public Health and the Environment. The study sponsors had no role in: the design and conduct of the study; collection, management, analysis and interpretation of the data; the preparation, review or approval of the manuscript; or the decision to submit the manuscript for publication.

Duality of interest The authors declare that there is no duality of interest associated with this manuscript.

Contribution statement AHW, HAS and NEB conceived and conceptualised the study. NEB performed data analysis and interpretation and wrote the first draft of the manuscript. BvN assisted in data preparation and analysis, and reviewed and revised the manuscript. AHW, LvR, GHK, UG, AMWS and HAS made a substantial contribution to data analysis and interpretation, and reviewed and revised the manuscript. All authors approved the final version of the article. NEB is the guarantor of this work and, as such, had full access to all of the study data and takes responsibility for data integrity and the accuracy of data analysis.

\section{References}

1. Pandey AK, Pandey S, Blaha MJ et al (2013) Family history of coronary heart disease and markers of subclinical cardiovascular disease: where do we stand? Atherosclerosis 228:285-294

2. Kardia SL, Haviland MB, Sing CF (1998) Correlates of family history of coronary artery disease in children. J Clin Epidemiol 51:473-486

3. Valdez R, Greenlund KJ, Khoury MJ, Yoon PW (2007) Is family history a useful tool for detecting children at risk for diabetes and cardiovascular diseases? A public health perspective. Pediatrics 120(Suppl 2):S78-S86

4. Harrison TA, Hindorff LA, Kim H et al (2003) Family history of diabetes as a potential public health tool. Am J Prev Med 24:152-159

5. Rosenbaum M, Nonas C, Horlick M et al (2004) Beta-cell function and insulin sensitivity in early adolescence: association with body fatness and family history of type 2 diabetes mellitus. J Clin Endocrinol Metab 89:5469-5476

6. Wei JN, Li HY, Wang YC et al (2010) Detailed family history of diabetes identified children at risk of type 2 diabetes: a populationbased case-control study. Pediatr Diabetes 11:258-264 
7. Srinivasan SR, Frontini MG, Berenson GS, Bogalusa Heart Study Group (2003) Longitudinal changes in risk variables of insulin resistance syndrome from childhood to young adulthood in offspring of parents with type 2 diabetes: the Bogalusa Heart Study. Metab Clin Exp 52:443-450

8. Anjana RM, Lakshminarayanan S, Deepa M, Farooq S, Pradeepa R, Mohan V (2009) Parental history of type 2 diabetes mellitus, metabolic syndrome, and cardiometabolic risk factors in Asian Indian adolescents. Metab Clin Exp 58:344-350

9. Levitan EB, Song Y, Ford ES, Liu S (2004) Is nondiabetic hyperglycemia a risk factor for cardiovascular disease? A meta-analysis of prospective studies. Arch Intern Med 164:2147-2155

10. Jarrett RJ (1984) Type 2 (non-insulin-dependent) diabetes mellitus and coronary heart disease - chicken, egg or neither? Diabetologia 26:99-102

11. Lim SS, Vos T, Flaxman AD et al (2012) A comparative risk assessment of burden of disease and injury attributable to 67 risk factors and risk factor clusters in 21 regions, 1990-2010: a systematic analysis for the Global Burden of Disease Study 2010. Lancet 380:2224-2260

12. Ezzati M, Lopez AD, Rodgers A, Vander Hoorn S, Murray CJ, Comparative Risk Assessment Collaborating G (2002) Selected major risk factors and global and regional burden of disease. Lancet 360:1347-1360

13. Hu FB, Manson JE, Stampfer MJ et al (2001) Diet, lifestyle, and the risk of type 2 diabetes mellitus in women. N Engl J Med 345:790-797

14. Stampfer MJ, Hu FB, Manson JE, Rimm EB, Willett WC (2000) Primary prevention of coronary heart disease in women through diet and lifestyle. N Engl J Med 343:16-22

15. Chang MH, Valdez R, Ned RM et al (2011) Influence of familial risk on diabetes risk-reducing behaviors among U.S. adults without diabetes. Diabetes Care 34:2393-2399

16. Wijga AH, Kerkhof M, Gehring U et al (2014) Cohort profile: the prevention and incidence of asthma and mite allergy (PIAMA) birth cohort. Int J Epidemiol 43:527-535

17. Expert Panel on Integrated Guidelines for Cardiovascular Health and Risk Reduction in Children and Adolescents; National Heart, Lung, and Blood Institute (2011) Expert panel on integrated guidelines for cardiovascular health and risk reduction in children and adolescents: summary report. Pediatrics 128(Suppl 5):S213-S256

18. InterAct Consortium, Scott RA, Langenberg C et al (2013) The link between family history and risk of type 2 diabetes is not explained by anthropometric, lifestyle or genetic risk factors: the EPICInterAct study. Diabetologia 56:60-69

19. Scheuner MT, Wang SJ, Raffel LJ, Larabell SK, Rotter JI (1997) Family history: a comprehensive genetic risk assessment method for the chronic conditions of adulthood. Am J Med Genet 71:315-324

20. Fredriks AM, van Buuren S, Burgmeijer RJ et al (2000) Continuing positive secular growth change in The Netherlands 1955-1997. Pediatr Res 47:316-323

21. Cole TJ, Bellizzi MC, Flegal KM, Dietz WH (2000) Establishing a standard definition for child overweight and obesity worldwide: international survey. BMJ 320:1240-1243

22. Pickering TG, Hall JE, Appel LJ et al (2005) Recommendations for blood pressure measurement in humans and experimental animals: Part 1: blood pressure measurement in humans: a statement for professionals from the Subcommittee of Professional and Public Education of the American Heart Association Council on High Blood Pressure Research. Hypertension 45:142-161
23. Petersen AC, Crockett L, Richards M, Boxer A (1988) A self-report measure of pubertal status: reliability, validity, and initial norms. J Youth Adolesc 17:117-133

24. Bao W, Srinivasan SR, Wattigney WA, Berenson GS (1995) The relation of parental cardiovascular disease to risk factors in children and young adults. The Bogalusa Heart Study. Circulation 91:365371

25. Morrison JA, Glueck CJ, Wang P (2012) The child as proband for future parental cardiometabolic disease: the 26-year prospective Princeton Lipid Research Clinics Follow-up Study. J Pediatr 160: 590-597

26. Shear CL, Webber LS, Freedman DS, Srinivasan SR, Berenson GS (1985) The relationship between parental history of vascular disease and cardiovascular disease risk factors in children: the Bogalusa Heart Study. Am J Epidemiol 122:762-771

27. Scheuner MT, Setodji CM, Pankow JS, Blumenthal RS, Keeler E (2008) Relation of familial patterns of coronary heart disease, stroke, and diabetes to subclinical atherosclerosis: the multi-ethnic study of atherosclerosis. Genet Med 10:879-887

28. Murabito JM, Nam BH, D'Agostino RB Sr, Lloyd-Jones DM, O'Donnell CJ, Wilson PW (2004) Accuracy of offspring reports of parental cardiovascular disease history: the Framingham Offspring Study. Ann Intern Med 140:434-440

29. Weijmans M, van der Graaf Y, Reitsma JB, Visseren FL (2015) Paternal or maternal history of cardiovascular disease and the risk of cardiovascular disease in offspring. A systematic review and meta-analysis. Int J Cardiol 179:409-416

30. Abbasi A, Corpeleijn E, van der Schouw YT et al (2012) Parental history of type 2 diabetes and cardiometabolic biomarkers in offspring. Eur J Clin Invest 42:974-982

31. Silberberg J, Fryer J, Wlodarczyk J, Robertson R, Dear K (1999) Comparison of family history measures used to identify high risk of coronary heart disease. Genet Epidemiol 16:344-355

32. Murad H, Kalter-Leibovici O, Chetrit A, Freedman LS (2007) A statistical comparison of different family history scores. Stat Med 26:2785-2798

33. Stampfer MJ, Sacks FM, Salvini S, Willett WC, Hennekens CH (1991) A prospective study of cholesterol, apolipoproteins, and the risk of myocardial infarction. N Engl J Med 325:373-381

34. Verweij LM, Terwee CB, Proper KI, Hulshof CT, van Mechelen W (2013) Measurement error of waist circumference: gaps in knowledge. Public Health Nutr 16:281-288

35. Chen X, Wang Y (2008) Tracking of blood pressure from childhood to adulthood: a systematic review and meta-regression analysis. Circulation 117:3171-3180

36. Juonala M, Magnussen CG, Venn A et al (2010) Influence of age on associations between childhood risk factors and carotid intimamedia thickness in adulthood: the Cardiovascular Risk in Young Finns Study, the Childhood Determinants of Adult Health Study, the Bogalusa Heart Study, and the Muscatine Study for the International Childhood Cardiovascular Cohort (i3C) Consortium. Circulation 122:2514-2520

37. McCarron P, Smith GD, Okasha M, McEwen J (2000) Blood pressure in young adulthood and mortality from cardiovascular disease. Lancet 355:1430-1431

38. Edwards A, Hood K, Matthews E et al (2000) The effectiveness of one-to-one risk communication interventions in health care: a systematic review. Med Decis Making 20:290-297 